\title{
Does withdrawing treatment from a pregnant persistent vegetative state patient resulting in her death constitute a termination of pregnancy?
}

\author{
D McQuoid-Mason, BComm LLB, LLM, PhD \\ David McQuoid-Mason is Professor of Law at the Centre for Socio-Legal Studies, University of KwaZulu-Natal, Durban, South Africa, and publishes and \\ teaches in medical law
}

Corresponding author:D McQuoid-Mason (mcquoidm@kzn.ac.za)

\begin{abstract}
A recent article on the Texas case of Munoz v. John Peter Smith Hospital, begs the question of whether if the pregnant woman had been in a persistent vegetative state (PVS) the courts in South Africa would have ordered the withdrawal of life-support treatment because she had expressed her wish not to be treated under such conditions in an advance directive, and that keeping her alive against her wishes would violate her constitutional rights to equality, dignity, privacy and bodily integrity. The answer seems to be yes in both instances. This applies even if the withdrawal of such support is opposed by the persons legally capable of consenting on her behalf in terms of the National Health Act. Where there is no advance directive - provided the treating clinicians conclude that any further treatment will be futile or that the benefits of further treatment are outweighed by the burdens and risks involved - life-support treatment may be withdrawn even against the wishes of persons entitled to consent on her behalf in terms of the National Health Act. Such legally competent persons may, however, apply to court to prevent the implementation of the decision of the clinicians.
\end{abstract}

SAfr J BL 2015;8(1):8-10. DOI:10.7196/SAJBL.336

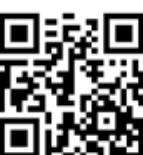

In the Texas case of Munoz v. John Peter Smith Hospital, ${ }^{[1]}$ the court granted a husband a court order for the removal of 'life support'from his brain-dead pregnant wife whose body was decaying, after a hospital had tried to keep her on 'life support' until the fetus was born. It has been suggested that a South African (SA) court would have come to a similar decision but for different reasons. ${ }^{[2]} \mathrm{A}$ recent article commenting on the Munoz case ${ }_{1}^{[3]}$ begs the question of whether if the pregnant woman had been in a persistent vegetative state (PVS) the courts in South Africa would have reached the same conclusion on the basis that she had expressed her wish not to be kept alive in an advance directive, and that keeping her alive against her wishes would have been a violation of her constitutional rights to equality, dignity, privacy and bodily integrity. ${ }^{[3]}$

To answer this question it is necessary to consider the following in the context of SA law:

- the meaning of 'persistent vegetative state'

- the constitutional rights of PVS patients

- the legal status of advance directives

- when life support treatment may be withdrawn from PVS patients

- whether such withdrawal of treatment from a pregnant PVS patient, that results in the death of the fetus, constitutes a termination of pregnancy

- whether the fetus has any legal right to be kept alive in its PVS mother until birth.

\section{Meaning of persistent vegetative state}

Persistent vegetative state has been described by the SA courts ${ }^{[4]}$ as 'a neurological condition where the subject retains the capacity to maintain the vegetative part of the neurological function but has no cognitive function'. The body 'functions entirely in terms of its internal controls' and 'maintains digestive activity, the reflex activity of muscles and nerves for low level and primitive conditioned responses to stimuli, blood circulation, respiration and certain other biological functions but there is no behavioral evidence of either self-awareness or awareness of the surroundings in a learned manner.[4]

Although PVS patients are not mentally capable of making decisions for themselves because they are brain-damaged rather than brain-dead, they are still alive and entitled to all the legal rights and protections of natural persons that are set out in the Constitution. ${ }^{[5]}$

\section{Constitutional rights of PVS patients}

In terms of the Constitution ${ }^{[5]}$ PVS patients have the same rights as anyone else to equality (section 9), dignity (section 10), life (section 11 ), bodily security (section 12) and privacy (section 14). However, although the right to life in the Constitution (section 11) may not be derogated from, in a situation where a patient has refused livesaving medical treatment, or further medical treatment is futile ${ }^{[4]}$ or unavailable because of a shortage of resources, ${ }^{[6]}$ the court is likely to regard such derogation as legally justifiable. ${ }^{[4]}$

Therefore if a PVS patient has made an advance directive regarding withholding or withdrawal of life-saving treatment this should be respected or at least taken into account. ${ }^{[4]}$ Likewise, if further lifesaving treatment is futile it may be withdrawn. ${ }^{[4]}$ Furthermore, if there is a shortage of medical resources necessary to provide lifesupport for a PVS patient and the criteria for refusing to provide such life-saving medical treatment are reasonable and justifiable, such treatment may be withheld or withdrawn. ${ }^{[6]}$ 


\section{Legal status of advance directives}

The courts have not yet pronounced on the legality of advance directives such as 'living wills', but have indicated that such directives may be taken into account when determining a PVS patient's wishes. ${ }^{[4]}$ The SA Law Commission has made recommendations regarding the statutory recognition of 'living wills, ${ }^{\prime}[7]$ but such recommendations have not yet been included in legislation. Until such time as suitable legislation is passed, 'living wills' may be recognised using common law principles, in situations where the medical practitioner concerned is satisfied that the conditions in the 'living will'for withholding or withdrawing treatment have been met and that such a will reflects the current wishes of the patient. ${ }^{[8]}$

Where there are no directions in the patient's'living will' concerning her wishes should she be pregnant at the time she becomes PVS, in terms of the National Health Act ${ }^{[9]}$ a court appointed curator, or her spouse or partner, parent or grandparent, adult child or adult sibling - in that order of priority - may make a decision on her behalf (section 7(1)(b)). The same applies to a proxy appointed by her in writing in terms of the National Health Act to act on her behalf should she become mentally incapacitated (section $7(1)(a)(i))$.

The Health Professions Council of South Africa recognises the value of 'living wills', and in its Guidelines for the Withholding and Withdrawing of Treatment states that patients 'should be given the opportunity and be encouraged to indicate their wishes regarding further treatment and to place in writing their directives for future care in possible critical circumstances', and that an 'appropriately drafted "living will" may be used for this purpose.[10]

\section{When life support treatment may be withdrawn from PVS patients}

Life support treatment may be withdrawn from PVS patients in three situations:

- where a patient has made an advance directive (e.g. a 'living will')

- when the treating clinicians conclude that any further treatment will be futile because the patient is dying from an irreversible condition ${ }^{[4]}$

- when, after discussions with the patient's next-of-kin, an agreement is reached that the benefits of further treatment are outweighed by the burdens and risks involved. ${ }^{[1]}$

If the PVS patient is pregnant the treating doctors should respect the patient's advance directive to withhold or withdraw treatment if the conditions for such termination are satisfied and the directive includes a clause that covers pregnancy situations. If the advance directive contains no such clause the physicians should obtain consent from the patient's curator, next-of-kin (in the order of priority set out in the National Health Act) ${ }^{[9]}$ (section $\left.7(1)(b)\right)$, or nominated proxy as mentioned above (section 7(1)(a)(i)).

Where the prognosis for both the PVS patient and the developing fetus is hopeless and attempts to provide life support for mother and fetus until full term will be futile, or the burdens and risks outweigh the benefits to the patient, the doctors may withhold or withdraw treatment - even against opposition by the persons legally able to consent to withholding or withdrawal of treatment. ${ }^{[11]}$ In such cases the persons concerned should be given the opportunity to transfer the patient to another facility where such treatment is available, or if necessary to apply for a court order to prevent the withholding or withdrawal of treatment. Where they decide not to transfer the patient or not to apply for a court order - provided that the doctors are satisfied that treatment is futile, or the burdens and risks outweigh the benefits to the patient, and this is confirmed by an independent health care practitioner - the treatment may be withheld or withdrawn. ${ }^{[12]}$

\section{Does withdrawal of treatment from a pregnant PVS patient resulting in the death of the fetus constitute a termination of pregnancy in terms of the Choice on Termination of Pregnancy Act?}

The Choice on Termination of Pregnancy Act ${ }^{[12]}$ defines a termination of pregnancy as 'the separation and expulsion, by medical or surgical means, of the contents of the uterus of a pregnant woman' (section 1). Therefore, unless a termination of pregnancy procedure is used to separate or expel the fetus of a PVS pregnant woman, the Choice Act does not apply.

If life support treatment is withheld or withdrawn from a PVS pregnant patient with the result that she dies and the fetus with her, this is not classified as a termination of pregnancy for the purposes of the Choice Act. It is merely the natural consequence of a pregnant PVS mother dying. ${ }^{[2]}$

\section{Does a fetus have a legal right to be kept alive in its PVS mother until it is born?}

The fetus is not regarded as a person in SA law and is not protected by the Constitution or the common law unless it is born alive. ${ }^{[13]}$ The courts have held that there are no legal grounds for the appointment of a curator to represent a fetus in cases where its mother wishes to terminate a pregnancy. Therefore, nobody will be appointed by the court to ensure that the fetus of a PVS mother is kept alive until it is born. ${ }^{[13]}$ However, if the prognosis indicates the healthy development of the fetus until it is born - and with the consent of the persons who have legal capacity to consent to treatment on behalf of the PVS patient in terms of the National Health Act - the doctors concerned may provide life-support to the PVS mother until the child is born. ${ }^{[2]}$

\section{Conclusion}

Where a pregnant PVS patient has expressed in an advance directive her wish not to be subjected to life support treatment - even if pregnant - keeping her alive against her wishes would be a violation of her constitutional rights to equality, dignity, privacy and bodily integrity.

If a pregnant PVS patient had not made an advance directive requesting withholding or withdrawal of treatment while pregnant she may be subjected to life-support until the baby is born with the consent of her curator, next-of-kin or proxy as provided for in the National Health Act - provided that carrying the fetus to term is medically justifiable.

Where the prognosis for a PVS pregnant patient and her fetus is hopeless, and the treating clinicians conclude that any further treatment will be futile or the benefits of further treatment are outweighed by the burdens and risks involved, the life-support treatment may be withheld or withdrawn - even if it is against the wishes of the curator, next-of-kin or proxy legally competent to consent in terms of the National Health Act. However, such persons must be given the opportunity to transfer the PVS patient to another 
health facility or may apply for a court order should they wish contest the decision of the clinicians.

\section{References}

1. Munoz v. John Peter Smith Hospital, Tarrant County District Court, Texas, 24 January 2014 (unreported). Sapa-AP-AFP. Switch off my dead wife, plea. The Mercury 28 January 2014:5

2. McQuoid-Mason DJ. Terminating the pregnancy of a brain-dead mother. S Afr J BL 2014:7(2):44-46. [http://dx.doi.org/10.7196/SAJBL.317]

3. Nienaber A. Pregnant, dead, and on a ventilator: A few thoughts in response to Prof McQuoid-Mason. S Afr J BL 2014:7(2):47-50. [http://dx.doi.org/10.7196/SAJBL.330] 4. Clarke v. Hurst NO 1992 (4) 636 (D).

5. Republic of South Africa. Constitution of the Republic of South Africa. Government Gazette 1996.
6. Soobramoney v. Minister of Health, KwaZulu-Natal 1998 (1) SA 765 (CC).

7. Republic of South Africa. Euthanasia and the artificial preservation of life. Paper 71: Project 86. Pretoria: South African Law Commission, 1997.

8. McQuoid-Mason D. The legal aspects of the Living Will. Continuing Medical Education 1993:59(11):59-64.

9. Republic of South Africa. The National Health Act. Pretoria: Government Gazette 2004

10. Health Professions Council of South Africa. Guidelines for the Withholding and Withdrawing of Treatment. Pretoria: HPCSA 2008: paragraph 2.3.

11. McQuoid-Mason D. Withholding or withdrawal of treatment and palliative treatment hastening death: The real reason why doctors are not held legally liable for murder. S Afr Med J 2014;104:102-103. [http://dx.doi.org/10.7196/ samj.7405]

12. Republic of South Africa. Choice on Termination of Pregnancy Act No. 92, Pretoria: Government Gazette 1996.

13. Christian Lawyers Association of South Africa v. Minister of Health 1998(4) SA $1113(\mathrm{~T})$. 